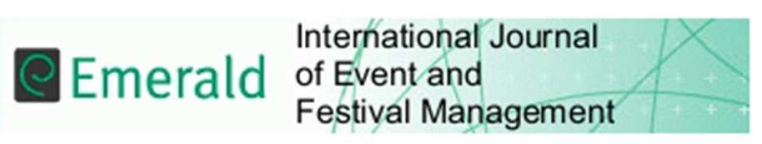

\title{
Perspectives of Event Leveraging by Restaurants and City Officials
}

\begin{tabular}{|r|l|}
\hline Journal: & International Journal of Event and Festival Management \\
\hline Manuscript ID & IJEFM-01-2017-0001 \\
\hline Manuscript Type: & Research Paper \\
\hline Keywords: & leveraging, sport tourism, small scale events \\
\hline \multicolumn{2}{|l}{} \\
\hline
\end{tabular}

\footnotetext{
SCHOLARONE ${ }^{\text {Ix }}$

Manuscripts
} 
EVENT LEVERAGING

\section{Purpose}

Hosting events can attract visitors to an area and provide an opportunity for local businesses in the host community to benefit economically. Restaurants, in particular, have an opportunity to benefit as food is a necessary expenditure. However, previous research suggests that the intentional attraction of event visitors by local businesses has been minimal. The purpose of this study was to explore perspectives of event leveraging held by restaurant owners/managers and a destination marketing organization.

\section{Design/methodology/approach}

Data were collected through semi-structured interviews with owners/managers of 16 local restaurants and from three destination marketing organization (DMO) executives in one medium sized city in Ontario, Canada. Data were analyzed using the constant comparison method.

\section{Findings}

Findings suggest that restaurants' interest in event leveraging was tied to their beliefs about whether initiatives would be successful. They believed that success was likely based on three different conditions: (i) belief in benefits from leveraging; (ii) proximity to event or host hotel; and (iii) being prepared for event leveraging opportunities. The DMO had a desire to assist local business in leveraging, but their ability to do so was negatively impacted by a lack of awareness of events being hosted, disengagement by local businesses, and limited resources.

\section{Originality/value}

Findings suggest there is a need for DMO's and local businesses to create stronger and more supportive working relationships with each other in order to achieve success from event leveraging. 
Keywords. Leveraging, small scale events; sport tourism 
EVENT LEVERAGING

\section{Perspectives of Event Leveraging by Restaurants and City Officials}

Hosting sport events have the potential to provide local businesses with tourism-related benefits through visitor spending if the event is strategically leveraged (Misener, Taks, Chalip, \& Green, 2015; O’Brien \& Chalip, 2008). Event leveraging refers to strategic and intentional tactics that seek to derive benefits from the hosting of sport events. Yet, few local businesses engage in leveraging tactics to maximize the impact they receive (Chalip \& Leyns, 2002; Smith, 2010; Mackellar, 2015). Smaller, non-mega sport events represent a significant opportunity for leveraging efforts because many communities already hold such events annually and disruptions to host communities and use of tax dollars are minimal (Smith, 2010; Taks, 2013). However, research on the leveraging potential of small scale, non-mega sport events remains underexplored (O’Brien, 2007; Smith, 2010; Taks, 2013). Central to the strategic planning process involved in leveraging is an understanding of why local businesses choose to engage (or not) in leveraging (Mackellar, 2015). Restaurants are a particularly relevant stakeholder group because food is a required purchase for travelers and event attendees typically have the freedom to select where they dine (Taks, Green, Chalip, Kesenne, \& Martyn, 2013). Practically, an understanding of restaurants' perspectives may assist in the development of strategies by city officials to educate, support, or encourage leveraging. Thus, this study develops an understanding of perspectives about event leveraging held by restaurant owners/managers and executives at a destination marketing organization in order to capitalize on opportunities from hosting smaller scale events in host communities. The present study addresses a growing need for research into factors and conditions necessary for sport events to have beneficial outcomes in host communities (Coalter, 2007). 


\section{Literature Review}

Recognizing that sport events do not always produce significant benefits for the host community (Coalter, 2004), a line of research termed event leveraging emerged that takes a prospective approach by suggesting that benefits can be achieved if sport events are leveraged effectively through a number of tactics and strategies (Beesley \& Chalip, 2011; Chalip \& Leyns, 2002; Chalip, 2006, 2014; O’Brien, 2007; Taks, Chalip, Green, Kesenne, \& Martyn, 2009). On an immediate basis, host communities can seek to benefit economically through leveraging by enticing visitor spending, lengthening visitor stays, and retaining event expenditures (Chalip, 2004).

\section{Means of Immediate Leveraging}

There are various tactics that can be employed to leverage events to achieve economic benefits. Recent work has identified that visitors will stay longer in a particular location prior to and following an event if they are made aware of desired attractions in the host destination (Taks et al., 2009). As a result, bundling sport events with other host destination attractions is one approach that can be utilized to effectively leverage the event. Bundling involves combining services and/or products into a single package for a reduced price. Bundling can result in increased awareness, a simplification of the information search and purchase decisions, perceived discounts on prices and the increased appeal of the host destination (Naylor \& Frank, 2001). For example, destinations can bundle sport events into a package with sightseeing tours, visits to shopping areas and restaurant districts, and entrances to attractions in the area. As visitors at an event may have different motivations for attendance, it has been suggested that ancillary activities that match their consumer profiles should be promoted (Snelgrove \& Wood, 2010). For example, some sport event attendees can be presented with an opportunity to 
celebrate their event identities with similar others, and for those who are not attached or connected to the sport, the addition of music, dance, theatre, and/or art exhibitions might appeal to this segment of attendees (Chalip \& McGuirty, 2004). These ancillary activities may entice visitors to spend money, lengthen their stays, enhance their event experience and even promote positive word of mouth about the destination (Taks et al., 2009; Xing, Chalip, \& Green, 2014).

Another means of leveraging can be through the use of subcultural aspects of the sports at hand in an effort to encourage visitors to spend money within the community. This requires host communities and event organizers to identify the subcultures that may exist within the sport and then local businesses can use this information in the design of related ancillary activities (Chalip \& McGuirty, 2004; Green, 2001; O’Brien, 2007; Xing et al., 2014). In a study of the Gold Coast Honda Indy, Chalip and Leyns (2002) found that few local businesses identified the event as a potential leveraging opportunity. However, their research found that those who did leverage the event by creating themed activities found the tactic to be effective. Chalip and Leyns concluded that local businesses can be successful if they partner with other businesses to create themed areas that enable visitors to celebrate their shared event identity, develop an understanding of the consumers' preferences, and create targeted promotional campaigns that appeal to visitors.

Similarly, Xing et al. (2014) demonstrated that the development of a sense of community among sport event tourists was predictive of spending at local restaurants and shops.

\section{Achieving Strategic Objectives}

Despite the potential of increased revenues that can be achieved, few local businesses are leveraging events (Chalip, 2014; Chalip \& Leyns, 2002; Mackellar, 2015). Indeed, reasons for limited engagement in strategic leveraging has received limited empirical attention from sport researchers. Thus, there is a need to identify reasons why efforts are not undertaken by local 
businesses to entice visitor spending. Clearly, different stakeholders in a community can play a role in enacting leveraging tactics (e.g., event organizers, city officials, local organizations; Chalip \& Leyns, 2002; Mackellar, 2015; Taks et al., 2014). However, one of the main beneficiaries of economic benefits, and thus of leveraging are local businesses in the host community where visitors will spend money (Chalip \& Leyns, 2002). Hence, local businesses have a potential interest in employing leveraging tactics for direct benefit.

However, the willingness to undertake leveraging practices may rely upon a number of factors. One of the few studies that has examined the reasons behind engagement or lack of engagement in leveraging by local businesses and destinations highlighted six domains affecting involvement in leveraging (i.e., Mackellar, 2015). The six domains identified by Mackellar were (1) event cooperation (e.g., coordinated engagement of all stakeholders in a community involved in creating an event and tourist experience), (2) tourism dependency (e.g., the percentage of sales directed toward visitors and perceived impact on regular customers), (3) business type (e.g., perceived appeal to event visitors), (4) promotional strategy (e.g., perceived fit with overall marketing strategy of business or parent company), (5) strategic direction (e.g., viewed as a contribution to the community), and (6) skills, knowledge and inertia (e.g., knowledge to execute and responsibility for coordinated efforts). Mackellar found variation within each of these domains, thereby highlighting both success factors and constraints to leveraging engagement. Similarly, Chalip and Leyns (2002) examined the leveraging efforts of local businesses (e.g., accommodation, retail and restaurants) in the context of the Gold Coast Honda Indy. Specifically, they investigated their reasons for leveraging, and the reasons why local merchants chose not to leverage. Only 8 of the 22 businesses in their study engaged in leveraging, and for most the tactics employed were very minimal (e.g., including a picture of the event in brochures, 
creating a sales table etc.). The reasons cited for not engaging in leveraging included location (i.e., those within the event location believed there would be high demand anyways and those outside the event precinct thought their efforts would be futile), not viewing event patrons as a viable market (i.e., businesses felt the event patrons would not be interested in shopping) and that the event pulled local residents away from their businesses through increased traffic and congestion. An example of event leveraging they found was a restaurant engaged in a coordinated theming strategy that was implemented together with the other local businesses in the neighborhood (i.e., they developed an auto racing theme for the entire area). Overall, the authors indicated that minimal leveraging strategies were utilized and most of the tactics employed were haphazard and limited to businesses that were in close proximity to the event precinct. As an additional phase of their study, Chalip and Leyns developed a taskforce, consisting of representatives from tourism, marketing, hotel management and an entrepreneur, to examine how the leveraging effort of local businesses could be enhanced. The taskforce concluded that businesses would need assistance in the creation and execution of leveraging strategies and that this would need to be accomplished through the development of business alliances. Finally, the taskforce suggested that a central coordinating body should be created to assist in the process.

In a study of leveraging the International Children's Games for sport development purposes, Taks et al. (2014) identified the reasons for failed implementation of leveraging tactics as a lack of human resource capacity and minimal collaborative action within the community. Similarly, a model on leveraging events for sport participation, developed by Chalip, Green, Taks, and Misener (2016), illustrated the necessity of adequate levels of human, financial and physical resources. Other studies identified that benefits derived from hosting sport events may 
vary based on stakeholder group and geographic proximity to the event, which suggests that some local businesses may stand to benefit from hosting events more than others (Potwarka \& Leatherdale, 2016; Taks, Girginov, \& Boucher, 2006).

Smith (2010) identified a number of factors critical to the successful implementation of event leveraging tactics. Notably, Smith advocated for the use of local champions to coordinate activities among key stakeholders and push for the creation of themed areas, the necessary engagement of local businesses to be a part of creating themed areas, the development of relationships among key stakeholders, and the commitment of resources by city officials to supporting leveraging efforts.

Notwithstanding the contributions previously identified, there remains a limited understanding of local businesses' perspectives related to event leveraging. Specifically, little research has identified the perspectives held by local restaurants and DMOs, or perspectives held in the context of non-mega events. Thus, the purpose of this study is to explore the perspectives of local restaurants and a supporting DMO about leveraging non-mega events in one community in Ontario, Canada.
Method
Research Setting
The context for this study was three medium sized multi-sport events that were hosted in one medium sized community in Ontario, Canada. These events took place over two summers and included the following: the 2013 International Children's Games (ICG), the 2014 Ontario Summer Games (OSG) and the 2014 55+ Ontario Summer Games (55+). Specifically, the ICG is an Olympic Committee sanctioned event that is hosted annually for athletes 12 to 15 years of age. Hosting communities are responsible for determining the sports that will be contested at 
each event. The 2013 event involved 8 sports (4 individual and 4 team) at 12 venues throughout the community. The event hosted 1,600 participants representing 80 cities and 31 countries (Guthrie, 2013).

The OSG is a multi-sport event that until recently was hosted by Sport Alliance Ontario (SAO). The event is contested on even years and is a provincially based competition. The 2014 OSG involved 19 sports (e.g., baseball, basketball, box lacrosse, soccer, skeet shooting) at 16 venues throughout the community. The 2014 event hosted 2,100 athletes ranging in age from 13 to 20 years (Waddell, 2014, Aug. 7).

Last, the $55+$ is a provincial event that is held bi-annually (with the winter games taking place in alternate years). The $55+$ is a multi-sport event that is hosted by the Ontario Senior Games Association. The purpose of the organization and the event is to promote active lifestyles for adults 55+ who are not engaging in sport at a more advanced or masters level (Ontario Senior Games Association, n.d.). The 2014 event involved 18 sports (e.g., lawn bowling, cycling, swimming, pickleball) at 10 venues around the community. The event hosted 1,400 athletes aged $55+$ for two days of competitions. For all three events described, communities actively engage in a coordinated bidding process to earn the right to be a host.

\section{Data Collection}

Data were collected in a three-step process. First, in 2013 three interviews were conducted with senior officials (i.e., CEO and two vice-presidents) at the region's destination marketing organization (DMO). Second in 2013, a total of 8 local restaurant owners or managers were interviewed around the time of the ICGs. Third, an additional 8 owners or managers at different restaurants were interviewed in 2014 around the time of the OSG and 55+ to further test and refine the emergent themes developed after the first year of data collection (Charmaz, 2006). 
The data collection in year two was also beneficial because the two events had very different target markets (as described previously) allowing the researchers to increase the generalizability of the findings. Restaurant types included fast food locations, sit down family style, casual dining, pubs, and more upscale experiences. Seven of the restaurants were located in the downtown core of the city, seven were located close to the event facilities, and two were located by the main shopping mall in the community. In total, 19 semi-structured interviews were conducted.

Interviews focused on perspectives about leveraging in the context of the identified sport events. The DMO was selected because it was, at the time of the study, the only coordinating organization with dedicated staff attempting to engage in leveraging and interact with local businesses. There was no sports council in operation, nor was there a paid employee in charge of coordinating sport events or leveraging. Restaurants were selected based on proximity to the venues (both nearby and farther away), and a reasonable possibility of leveraging the event (i.e., commonly frequented location for visitors, not a specialty business). Interviews were conducted at a time of the participants' choice and ranged in length from approximately 30 to 80 minutes. All interviews were transcribed verbatim.

\section{Data Analysis}

The data were analyzed in a staged process. The first stage of the analysis involved thematic line-by-line coding of the transcribed interviews conducted in year 1 . Two researchers undertook this coding process independently. The two researchers then met to discuss and resolve discrepancies and create final initial codes. The second stage involved these two researchers working together to develop broader themes from these initial codes. Third, data collected in year two were analyzed to test and refine the emergent themes (Charmaz, 2006). 
EVENT LEVERAGING

Consensus was reached among the researchers that initial emergent themes were represented well in the additional data, and theoretical saturation had been reached (Charmaz, 2006). Following the development of major themes, representative quotes were selected.

Trustworthiness of the data was established by sending participants the interview transcripts to confirm the accuracy of the data collected, having two researchers code the data independently, by providing extensive quotations throughout the findings section so the reader can assess the conclusions drawn, and collecting data in multiple years in the context of three different events (Lincoln \& Guba, 1985, 1986).

\section{Restaurants' Perspectives}

An analysis of the interview data from restaurants indicated that perspectives on event leveraging were tied to perceptions of whether it would lead to success. Restaurants believed that success was likely based on three different conditions, including belief in benefits from leveraging, proximity to event or host hotel, and being prepared for event leveraging opportunities. Further detail, representative quotes and pseudonyms are presented in the following section.

\section{Belief in Benefits from Event Leveraging}

Restaurants had to believe that benefits were theoretically possible before considering event leveraging ( $\mathrm{n}=12$ restaurants who mentioned belief in benefits), which in this case was largely shaped by their level of trust in claims made by city officials. In this regard, past claims and results from hosting events in the community were influential. More specifically, these study participants felt the city promised more benefits would accrue than were actually obtained. For example, Mike said, "We did see a slight increase of business but nothing like what we were supposedly promised." Similarly, thinking forward to the upcoming Ontario Summer Games, 
Mike reflected on his perceptions of the impact the International Children's Games had on his business and the city: "We were informed about what a great success they'd be for the city of Windsor and how they would be so beneficial to the businesses and blah blah blah. Because at the end of the day, it really sort of turned out to be blah... It wasn't really that big of a deal." The problems created by this lack of trust persists as more and more events are being hosted, as it becomes challenging for businesses to determine which events are worth the investment in light of the claims of benefits and attendance figures made by city officials. As George explained,

“it's hard to tell who knows what they're doing and who doesn't. I don't know for me if there was something where... either...say the Children's Games came again, I would say oh, I remember the Children's Games, that was great or I know what happens when there's a sporting event taking place in the downtown, we've done that before, we've seen it. So that if part of people's marketing to me was saying we're the people who did this in the past and that turned out, to help me realize that it's credible is one of the most important things.... So, discerning which ones are legitimate or at least semi-accurate in their estimates is tricky" (George)

Thus, findings suggest that many business owners and managers held skeptical perspectives about politicians' claims of benefits from hosting events.

Conversely, some $(n=3)$ restaurants felt that event leveraging was not tied to their success because they were expecting to be busy regardless. John explained his thinking by stating, "when it's more of a summer event ...we're a very busy restaurant in the summer ... it's our busy season, so when it comes to summertime we don't really like to throw too many things at it. ... 
EVENT LEVERAGING

for the Children's Games we just basically were open." Thus, for these restaurants the perceived benefits were minimal.

\section{Proximity to Event or Host Hotel}

Restaurants also mentioned proximity to the event or host hotel as a factor impacting leveraging success ( $n=11$ restaurants who mentioned proximity). The location of the event mattered a great deal to restaurants, as exemplified by Graham's comment that "the location of the event absolutely does matter; we're focused mainly on events that are in the downtown core." Additionally, John said, "you know the Ontario Summer Games, I think one of their major problems was that the events were not hosted downtown. I think the events if I recall they were hosted all over town... I believe they were all on the outskirts. I don't believe they came downtown." Conversely, some restaurants located downtown were quick to point out that it did not matter if the event was hosted outside of the downtown area, as long as participants and/or spectators were staying at downtown hotels because they would need to eat and shop when they were back at their hotel. Last, a few restaurants $(n=2)$ located outside of the downtown core did not view their restaurant as benefiting from tourism unless an event was specifically being held in their area: "I'll be honest, [visitors] kind of consider the west end kind of the ghetto, the student ghetto. So, I don't see it being a real tourist destination, kind of like downtown is more seen as a tourist destination" (Steve).

\section{Being Prepared for Event Leveraging Opportunities}

Last, restaurants indicated successful leveraging was predicated on an ability to adequately plan for such an undertaking ( $\mathrm{n}=11$ restaurants who mentioned being prepared). Restaurants primarily expressed a lack of awareness of sport events that had been recently held or were about to be held as a major reason why they did not engage in leveraging in the past. 
"I don't know who did any of the marketing or planning. ... I think most of the city was kind of caught off guard that a lot of them were coming because a lot of the local businesses didn't even know that they would be staying at the university or around the area or where the games were being held.” (Steve)

Similarly, Patricia said “we're not really doing a promotion because we didn't budget for it. We found out a little bit too late about it." These businesses said advanced awareness is important because it allows them to adequately budget for marketing tactics and operationally handle increased traffic. In most cases, businesses expressed a desire for the city to initiate communication about upcoming events. For example, John said, "I think they [the city] could do a better job informing people for sure.... I think they could do a little bit of a better job informing people about all of the events that happen in the city."

\section{DMO's Perspectives}

Senior officials at the DMO clearly articulated a desire to help local businesses successfully leverage the hosting of sport events. As Mark noted, they try to provide as much information as possible for visitors.

[Our goal is] to provide the most up to date information. So depending on how big the event is, sometime we'll promote by staff. For instance, we've done it twice now at the Aquatic Centre for big events where certain hours, if it's peak hours we'll provide a table there and we'll have visitor information specialists on site to have our visitor guides there, to have downtown maps there, if there's a question like hey where's [restaurant X] well here it is on the map, go for it. Let them know what's going on around the area, just have information available to people while they're here. 
Furthermore, for some events they have created initiatives that directly benefit select restaurants.

For example, Sarah described one such initiative for the 55+ Games.

We have a middle night and we thought how are we going to feed them? We've got a budget of $\$ 15$ from the registration fees to feed each athlete $\ldots$ and we thought why don't we try to create some economic impact for some of the downtown restaurants. So we created what's called a dine around program. We made these cards up that give $\$ 15$ value and we worked with the downtown BIA to get some of their members on board. They solicited all the restaurants who want to be involved and we have a list of I think 15 restaurants that want to be involved and they're willing to take these cards. They're worth $\$ 15$ and if they get turned in or redeemed they'll get the money back from the games. ... It creates a little bit more activity for the restaurants if they're willing to participate and take these cards. There's a huge pile that won't spend any more above that, maybe they'll order a beverage, you know but still it's putting that money into the restaurant's pockets.

Another approach to encouraging leveraging was through communication with local

restaurants. The DMO clearly recognized the importance of communicating with local businesses about upcoming events and described a number of methods employed to create awareness when they knew about events (e.g., email blasts, stories in media). Roger explained that in the past, "we gave [local businesses] a little workshop, we said okay, do this and this, we had speakers, we provided them with information to have and then we gave them a birder friendly sticker that they can put on their restaurant, their hotel." Mark reinforced this idea when he stated, "So, we're communicating with [the businesses] to let them know they're coming, embrace them, these are the events, where they're going to be, all of that information." 
EVENT LEVERAGING

When discussing the Ontario Summer Games specifically, Roger's team sent an "e-blast" that said,

be prepared, what are you doing for Ontario Summer Games? Let us know and we'll help put it on the website. So in other words, are you going to offer a special or whatever else so that's kind of a little bit of prep work to... and again get that connection and buy in in the community. Let everyone know they're coming.

However, there are very few additional examples of leveraging initiatives that have occurred in this community. The DMO's ability to assist with leveraging was impacted by a number of factors, including a lack of awareness, engagement by local businesses, and limited resources.

Lack of awareness. First, an awareness of events being hosted in the region was a necessary initial step for the DMO. As Mark suggested, "Certainly when we're aware of an organizer coming here what we do is we contact them to see, can we put together a weekend guide to what's happening in [the region] at that time." In reference to working with local businesses, Roger said,

We're trying to encourage local groups to work with our office because we could help from that perspective and then we can also help from a visitor services perspective. It's education. We're only as good as the information we know, if I don't know then I can't help you. Then don't complain about it.

Ultimately, though the first step in assisting local restaurants is the awareness that the event is taking place in the community. As Mark stated, "We're only as good as the information that comes to us."

Engagement by local businesses. However, from Roger's perspective, even if communication was improved and awareness of events was high, engagement in leveraging may 
not follow. He suggested, "As much as we can communicate with them, sometimes you're stuck with ... you're at their mercy, basically." Mark reinforced this idea when he said, "Really it's up to [the restaurants] to do what they want, we can give them ideas but at the end of the day we can't fund all this we can only...if you're the owner of a business we'll let you know what's coming and it's up to you to do whatever you want with it."

Unfortunately, as Sarah noted, not all restaurants view sport events as an opportunity to increase business and revenue and ultimately do nothing to attract the visitors that are in the community for the event. "We don't get a lot because it's hard when restaurant owners, it's such a small margin so there's not much going on with local restaurants for the Summer Games. Again, we didn't have much control or ability to do things." As a result, as Roger noted, all they can really do is inform the businesses and encourage them to engage in leveraging.

So while they're here we encourage the businesses to have welcome signs up, just to have a little logo of that event. That participant and/or parent knows that okay, I can go here, and they're embracing us. When they go in, maybe there's a specific menu. We're trying to encourage our local businesses to embrace these groups that are coming in to make them feel welcome and so there's a consistent message.

Limited resources. The ability of the DMO to implement leveraging tactics was also constrained by their budgets allocated to each event and the number of paid staff and volunteers and respective abilities. A number of times during the interviews, Sarah and Roger described leveraging tactics they could theoretically employ but were not able to because of limited funds or a lack of staff or capable volunteers. For example, Roger referenced the success of the past leveraging workshops they had done for a birder festival held in the past, but indicated that it would not be possible to do very often because of financial and staff limitations. Sarah described 
a number of efforts that were less than ideal because "we didn't really have much of a budget" which was viewed as a "challenge." Last, Mark described event theming initiatives that used to occur in the downtown area through the business improvement agency whereby welcoming event banners were posted and signs placed in the windows of retail locations and restaurants. Eventually, though, this effort ceased because they had a problem getting volunteers to continue doing it. 'It's work to sell it, but at the end of the day it certainly pays for itself. ... it would be nice if they were to do something more like that and then over time [it happened less often] to now nothing."

\section{Discussion and Implications}

Findings from this study provide an understanding of restaurants' and DMO executives' perspectives related to leveraging. Specifically, restaurants were primarily concerned with whether event leveraging would lead to business success (e.g., increased revenues). They believed that success was likely based on three different conditions, including belief in benefits from leveraging, proximity to event or host hotel, and being prepared for event leveraging opportunities. These sub-themes contribute to the extant literature on event leveraging by providing an idea as to why engagement in event leveraging may be minimal by local restaurants. Previous research has identified that organizations, such as local businesses (Mackellar, 2015) and sport organizations (Taks et al., 2014) are constrained by financial and human resources capacity when it comes to leveraging events. This study highlights similar challenges exist for DMOs (Gretzel, Fesenmaire, Formica, \& O’Leary, 2006; Karadakis, Kaplanidou, \& Karlis, 2010). Thus, despite the DMO’s best intentions to support event leveraging efforts by restaurants, they were constrained in their capacity to do so. Specific discussion of key findings and resulting implications for practice follows. 
EVENT LEVERAGING

Although restaurants expressed a greater interest in leveraging when they were close to the venue or the host hotel, many businesses close to the action were still reluctant to engage in leveraging. Thus, local businesses may benefit from being provided evidence and examples of past successes in theming and having a person responisble for coordinating theming efforts. In a study of a repeat event in one community, Chalip and Leyns (2002) found that some businesses eventually engaged in leveraging when they witnessed the benefits accrued to other businesses and they did not want to miss out on the opportunity provided by the event in subsequent years. Thus, efforts should be made to reduce uncertainty of outcomes from leveraging for local businesses.

Practically, event organizers are encouraged to develop and document an understanding of successful leveraging approaches undertaken in one community and share that information with future host cities so that local businesses unfamiliar with the event can make an informed decision rather than relying on the rhetoric exposed by local politicians or DMOs. This suggestion is particularly important as perspectives that challenge politicians' claims of positive economic impact and to whom the benefits accrue are increasingly common in the academic literature (e.g., Crompton \& Howard, 2013; Whitson \& Horne, 2006) and were articulated by study participants. The important role of educating local businesses on event leveraging was not lost on DMO officials in this study who highlighted past leveraging workshops they held in the region but were clearly constrained in executing based on available financial and human resources. Findings from the present study also suggest another strategy that may increase the confidence that claims being made are real, namely the establishment of continuity within organizing committees as local restaurants may be familiar with local figures and trust their ability to execute an event that provides the host community with economic benefits. 
One of the ways that businesses inside or outside of the event area can attract attendees is by working together to create a coordinated theming strategy that parallels the event to attract event attendees (Chalip \& Leyns, 2002; O’Brien, 2007; Smith, 2010). In such cases, attendees are able to celebrate their shared subculture beyond the event experience (Xing et al., 2014). Unfortunately, in the present study no coordinated strategies were undertaken by businesses within or outside of the event or host hotel area.

The inability to plan for the opportunity to leverage was also expressed by some of the businesses as a reason why they did not engage in leveraging. In some cases, participants were simply not aware the events were taking place, whereas in other cases participants found out too late. Participants identified that having this advanced awareness was important in order to budget for marketing materials and create an operational plan to deal with the increased traffic. This lack of awareness was echoed by DMO officials who expressed an ability to help only when they knew a sport event was being hosted. The finding that some businesses and even the DMO were not aware the events were taking place is troublesome and begs the question of whose responsibility it is to collect and provide the information (e.g., event organizers, other city officials, or the organizations themselves; Gretzel et al., 2006). Local businesses indicated a desire to hear from the city about upcoming events, whereas previous work has identified the event organizers as being the ones who should be responsible for this task (MacKellar, 2015).

Research has identified that cooperative activities are often coordinated and facilitated by sports councils, tourism agencies or destination marketing organizations (Stokes, 2006; Wasche $\&$ Woll, 2010). In order to assist in creating the event experience these organizations are fundamental in their roles of encouraging and facilitating cooperation between event organizers and businesses (Mackellar, 2015). In previous work, businesses have also identified the lack of 
EVENT LEVERAGING

communication and assistance from event organizers and suggested that this served as a barrier to event engagement (Mackellar, 2015). The businesses could also host auxillary events in collaboration with other businesses as an effective means of leveraging (O'Brien, 2006; Harrison-Hill \& Chalip, 2005), yet this opportunity was also not enacted upon in the current study and no benefits were realized for the restaurants.

Coordinating agencies (e.g., DMO’s, liaison officers between sport and tourism) play an important role in the development and implementation of programs that enable and assist businesses in accessing event sport tourists through structured initiatives (Weed, 2003). These initiatives serve to remove some of the barriers that businesses experience when attempting to benefit from the increased number of visitors in the community. Some of the restaurants in the current study identified a lack of awareness that sport events were taking place and thus, this would imply that the coordinating agencies in the community did not provide assistance with respect to programs and ideas for the restaurants to engage in leveraging of any kind. Whether it is the responsibility of the business, who may have lacked the necessary skills, or that of a coordinating agency, who may have lacked the necessary human resource capacity, an opportunity was missed. Thus, there is a need for DMO's and local businesses to create stronger and more supportive working relationships in order to achieve success (Kaplanidou \& Gibson, 2010; Ziakas \& Costa, 2010; Weed, 2003).

\section{Conclusion}

This study builds upon the existing event leveraging literature by identifying the conditions under which restaurant owners/managers are willing to engage in leveraging and the concurrent challenges faced by destination marketing organizations. From a local restaurant perspective, engagement in leveraging was tied to perceptions of potential success. A number of 
factors impacted the likelihood of success, including a belief in benefits from leveraging, proximity to event or host hotel, consistency with target market, and being prepared for event leveraging opportunities. These factors provide further understanding of the reasons for a lack of leveraging by local businesses despite potential benefits. From the local DMO's perspective, their desire to help local businesses benefit from the hosting of events was apparent but constrained by a number of factors including awareness of events being held, engagement by local businesses, and limited resources. If creating benefits for local business through events is seen as an important positive outcome of events, then cooperation among a supportive agency (e.g., DMO) and local businesses will need prioritized attention, as this will enhance leveraging engagement. 
EVENT LEVERAGING

\section{References}

Beesley, L. G., \& Chalip, L. (2011). Seeking (and not seeking) to leverage mega-sport events in non-host destinations: The case of Shanghai and the Beijing Olympics. Journal of Sport \& Tourism, 16, 323-341.

Chalip, L. (2004). Beyond impact: a general model for sport event leverage. In B.W. Ritchie \& D. Adair (eds.), Sport tourism, interrelationships, impacts and issues (pp. 226-252). Clevedon, UK: Channel View Publications.

Chalip, L. (2006). Towards social leverage of sport events. Journal of Sport \& Tourism, 11, 109127.

Chalip, L. (2014). From legacy to leverage. In J. Grix (Ed.), Leveraging legacies from sports mega-events: Concepts and cases (pp.1-12). New York: Palgrave MacMillan.

Chalip, L., Green, B.C., Taks, M., \& Misener, L. (2016). Creating sport participation from sport events: Making it happen. International Journal of Sport Policy and Politics, DOI: 10.1080/19406940.2016.1257496.

Chalip, L., \& Leyns, A. (2002). Local business leveraging of a sport event: Managing an event for economic benefit. Journal of Sport Management, 16, 132-158.

Chalip, L., \& McGuirty, J. (2004). Bundling sport events with the host destination. Journal of Sport \& Tourism, 9, 267-282.

Charmaz, K. (2006). Constructing grounded theory: A practical guide through qualitative analysis. Thousand Oaks, CA: Sage.

Coalter, F. (2004). Stuck in the blocks? A sustainable sporting legacy. In A. Vigor, M. Mean, \& C. Tims, After the Gold Rush: A sustainable Olympics for London (p. 93-108). London, UK: Institute for Public Policy Research/DEMOS. 
Coalter, F. (2007). A wider social role for sport: who's keeping the score? New York: Routledge.

Connell, J., \& Page, S. (2005). Evaluating the economic and spatial effects of an event: The case of the World Medical and Health Games. Tourism Geographies, 7, 63-85.

Crompton, L. J., \& Howard, D. R. (2013). Costs: The rest of the economic impact story. Journal of Sport Management, 27, 379-392.

Green, B. C. (2001). Leveraging subculture and identity to promote sport events. Sport Management Review, 4, 1-19.

Gretzel, U., Fesenmaire, D. R., Formica, S., \& O’Leary, J. T. (2006). Searching for the future: Challenges faced by destination marketing organizations. Journal of Travel Research, 45, 116-126.

Guthrie, J. (2013, November 25). 2013 Windsor-Essex International Children's game Status Report. Retrieved from http://www.citywindsor.ca/cityhall/City-CouncilMeetings/CouncilReports/Pages/CouncilReports2013.aspx

Harrison-Hill, T., \& Chalip, L. (2005). Marketing sport tourism: Creating synergy between sport and destination. Sport in Society: Cultures, Commerce, Media, Politics, 8, 302-320.

Kaplanidou, K., \& Gibson, H. J. (2010). Predicting behavioral intentions of active event sport tourists: The case of a small-scale recurring sports event. Journal of Sport \& Tourism, 15, 163-179.

Karadakis, K., Kaplanidou, K., \& Karlis, G. (2010). Event leveraging of mega sport events: A SWOT analysis approach. International Journal of Event and Festival Management, 1, $170-185$.

Lincoln, Y. S., \& Guba, E. G. (1985). Naturalistic inquiry. Beverly Hills, CA: Sage.

Lincoln, Y. S. \& Guba, E. G. (1986). But is it rigorous? Trustworthiness and authenticity in 
EVENT LEVERAGING

naturalistic evaluation. New Directions for Program Evaluation, 30, 15-25.

MacKellar, J. (2015). Determinants of business engagement with regional sport events. European Sport Management Quarterly, 15, 7-26.

Misener, K. \& Doherty, A. (2009). A case study of organizational capacity in nonprofit community sport. Journal of Sport Management, 23, 457-482.

Misener, L., \& Mason, D. S. (2006). Creating community networks: Can sporting events offer meaningful sources of social capital? Managing Sport \& Leisure, 11, 39-56.

Misener, L., Taks, M., Chalip, L., \& Green, B. C. (2015). The elusive "trickle-down effect" of sport events: Assumptions and missed opportunities. Managing Sport and Leisure, 20, $135-156$.

Naylor, G., \& Frank, K. E. (2001). The effect of price bundling on consumer perceptions of value. Journal of Services Marketing, 15, 270-281.

O’Brien, D. (2006). Event business leveraging: The Sydney 2000 Olympic Games. Annals of Tourism Research, 33, 240-261.

O’Brien, D. (2007). Points of leverage: Maximizing host community benefit from a regional surfing festival. European Sport Management Quarterly, 7, 141-165.

O’Brien, D. \& Chalip, L. (2008) Sport events and strategic leveraging: Pushing towards the triple bottom line. In A. G. Woodside \& D. Martin (Eds) Tourism Management: Analysis, Behaviour and Strategy, pp. 318-338 (Oxfordshire: CAB International).

Ontario Senior Games Association (n.d.). Retrieved from http://www.ontarioseniorgames.ca/ Potwarka, L. R., \& Leatherdale, S. (2016). The Vancouver 2010 Olympics and leisure-time physical activity rates among youth in Canada: Any evidence of a trickle-down effect? Leisure Studies, 35, 241-257. 
Smith, A. (2010). Leveraging benefits from major events: Maximising opportunities for peripheral urban areas. Managing Sport \& Leisure, 15, 161-180.

Snelgrove, R., \& Wood, L. (2010). Attracting and leveraging visitors at a charity cycling event. Journal of Sport \& Tourism, 15, 269-285.

Stokes, R. (2006). Network-based strategy making for events tourism. European Journal of Marketing, 40, 682-695.

Taks, M. (2013). Social sustainability of non-mega sport events in a global world. European Journal for Sport and Society, 10(2), 121-141

Taks, M., Chalip, L., Green, B. C., Kesenne, S., \& Martyn, S. (2009). Factors affecting repeat visitation and flow-on tourism as sources of event strategy sustainability. Journal of Sport \& Tourism, 14, 121-142.

Taks, M., Girginov, V, \& Boucher, B. (2006). The outcomes of coattail-marketing: The case of Windsor, Ontario and the Super Bowl XL. Sport Marketing Quarterly, 15, 232-242.

Taks, M., Green, B.C., Chalip, L., Kesenne, S., \& Martyn, S. (2013) Visitor composition and event-related spending. The International Journal of Event and Festival Management, $7(2), 132-147$.

Taks, M., Green, B. C., Misener, L., \& Chalip, L. (2014). Evaluating sport development outcomes: the case of a medium-sized international sport event. European Sport Management Quarterly, 14, 213-237.

Waddell, D. (2014, August, 7). Game on for 2014 Ontario Summer Games. The Windsor Star. Retrieved from: http://blogs.windsorstar.com/news/game-on-for-2014-ontariosummergames. 
EVENT LEVERAGING

Wasche, H., \& Woll, A. (2010). Regional sports tourism networks: A conceptual framework. Journal of Sport \& Tourism, 15, 191-214.

Weed, M. (2003). Why the two won't tango! Explaining the lack of integrated policies for sport and tourism in the UK. Journal of Sport Management, 17, 258-283.

Whitson D., \& Horne J. (2006). The glocal politics of sports mega-events: Underestimated costs and overestimated benefits? Comparing the outcomes of sports and mega-events in Canada and Japan. The Sociological Review, 54, 71-89.

Xing, X., Chalip, L., \& Green, B. C. (2014). Marketing a social experience: How celebration of subculture leads to social spending during a sport event. Sport Marketing Quarterly, 23, $138-147$.

Ziakas, V., \& Costa, C. A. (2010). Explicating inter-organizational linkages of a host community's events network. International Journal of Event and Festival Management, $1,132-147$. 